une revue Gallia

Rhône-Alpes | 2008

\title{
Lyon
}

4 et 6 rue du Mont d'Or

\section{Michèle Monin}

\section{(2) OpenEdition}

12 Journals

Édition électronique

URL : http://journals.openedition.org/adlfi/1828

ISSN : 2114-0502

Éditeur

Ministère de la culture

Référence électronique

Michèle Monin, "Lyon », ADLFI. Archéologie de la France - Informations [En ligne], Rhône-Alpes, mis en ligne le 01 mars 2008, consulté le 03 mai 2019. URL : http://journals.openedition.org/adlfi/1828

Ce document a été généré automatiquement le 3 mai 2019.

(c) Ministère de la Culture et de la Communication, CNRS 


\title{
Lyon
}

\author{
4 et 6 rue du Mont d'Or
}

\section{Michèle Monin}

Identifiant de l'opération archéologique : 9898

Date de l'opération : 2008 (SP)

1 La découverte fortuite d'un sarcophage gallo-romain en plomb des $111{ }^{\text {e }}$ s. - IV ${ }^{\text {e }}$ s. apr.J.-C. a nécessité une intervention de fouille d'urgence sur un terrain situé 4-6 rue du Mont d'Or, dans le 9e arrondissement de Lyon au mois de juillet 2008. Une opération de fouille préventive a été par la suite programmée sur l'emprise du projet et a permis la mise au jour en septembre-octobre 2008, de structures datées des premier et deuxième âges du fer ainsi qu'une occupation gallo-romaine (période augustéenne et $\mathrm{I}^{\mathrm{er}} \mathrm{s}$. apr. J.-C.). Le premier âge du fer est représenté par un regroupement de plusieurs maisons construites en structures légères sur poteaux. Les sols de circulation et foyers domestiques sont conservés et l'étude stratigraphique montre au moins deux états d'occupation. Le deuxième âge du fer est représenté par des structures fossoyées très riches en mobilier. Un fossé de cette période vient ceinturer un amoncellement de gros galets et blocs de gneiss au sein desquels a été retrouvé ce qu'il restait de la sépulture d'un adulte de plus de soixante ans. L'étude des bâtiments liés à l'Antiquité montre plusieurs états. À un habitat de structures légères succède un bâtiment sur piliers et murs construits en gneiss lié au mortier. Un incendie à la fin du $\mathrm{I}^{\mathrm{er}} \mathrm{s}$. apr. J.-C. vient détruire ces bâtiments et les remblais de démolition recouvrent l'ensemble du site.

2 MONIN Michèle 
INDEX

operation Sauvetage programmé (SP)

Index chronologique : âge du Fer, Ier siècle apr. J.-C., IIIe siècle apr. J.-C., IVe siècle apr. J.-C.

Index géographique : Rhône-Alpes, Rhône (69), Lyon (69123)

Thèmes : fossé, habitat, sarcophage, sépulture, trou de poteau

\section{AUTEUR}

\section{MICHÈLE MONIN}

Service archéologique de la Ville de Lyon 